\title{
The study of self-relationship and family attitudes and values in adult sportsman (on the example of ethnic and practicing Muslims)
}

\author{
ELMIRA I. MURTAZINA ${ }^{1} \triangle$, AIDA F. MINULLINA ${ }^{2}$ \\ ${ }^{1}$ Department of Pedagogical Psychology, Kazan (Volga Region) Federal University, Kazan, Russian Federation \\ 2Department of Clinical Psychology and Personality Psychology, Kazan (Volga Region) Federal University, Kazan, \\ Russian Federation
}

\begin{abstract}
The aim of this study is to identify the self-relationship and family attitudes and values correlation of professing Islam (practicing Muslims) and secular, ethnic Muslims in adolescence. The leading methods of this problem study are the theoretical analysis of scientific psychological literature as well as the empirical research method (testing), using techniques that allow to diagnose selfrelationships, family attitudes and values. The experiment involved 100 people: 50 men religiously practicing Muslims, 50 - ethnic Muslims. The average age of the subjects is $18-23$ years old. The study concludes that practitioners and ethnic Muslims have high self-relationship results in the components of "self-confidence", "self-esteem", "self-acceptance", "self-guidance." For religiously practicing Muslims there is no "internal conflict"; ethnic Muslims have high "internal conflict". The study of family attitudes revealed for both groups a strong focus on mainly joint activities in all areas of family life and a less loyal attitude to divorce, as well as for religiously practicing Muslims the importance of children's role in family life. Ethnic Muslims are characterized by personal identification with their spouse, social activity. The emotional and psychotherapeutic side of the family is important for them. And for practicing Muslims parent-educational attitude, personal identification with a spouse, and emotional-psychotherapeutic attitude are important. The study of terminal values has highlighted the importance of spiritual satisfaction, achievements, self-development for ethnic and practicing Muslims, as well as the importance of high material position for ethnic Muslims. Among life spheres, professional life and training are important for Muslims, for ethnic Muslims - the sphere of interests. The materials of this paper can be used by psychologists in working with students at Universities, Madrassas, Sunday and secondary schools. The relevance of the problem is due to the insufficient development of the correlation concept of self-relationship and family attitudes and values in adolescence (for example, ethnic and practicing Muslims). Despite there are many research options and methods for measuring it in this direction. The research materials are of practical value for psychological and pedagogical support in the educational process, as well as in the advisory work of young people who adhere to religious beliefs, observe the canons of Islam, or do not adhere to religious canons. The scientific novelty of the research problem and its originality is specified by the interest of self-consciousness, self-determination in adolescence, and family attitudes and values in the context of religious affiliation. Since juvenile period is a sensitive indicator of ongoing changes and determines the entire potential of the society development, the future of the society consequently depends greatly on the value foundation of the younger generation.
\end{abstract}

Keywords: Adult sportsman; Adolescence; Self-relation; Family attitudes; Family values.

Cite this article as:

Murtazina, E.I., \& Minullina, A.F. (2021). The study of self-relationship and family attitudes and values in adult sportsman (on the example of ethnic and practicing Muslims). Journal of Human Sport and Exercise, 16(3proc), S1197-S1206. https://doi.org/10.14198/jhse.2021.16.Proc3.36

Corresponding author. Department of Pedagogical Psychology, Kazan (Volga Region) Federal University, Kazan, Russian Federation.

E-mail: elil@inbox.ru

Abstract submitted to: Winter Conferences of Sports Science. Costa Blanca Sports Science Events, 22-23 March 2021. Alicante, Spain.

JOURNAL OF HUMAN SPORT \& EXERCISE ISSN 1988-5202.

(c) Faculty of Education. University of Alicante.

doi:10.14198/jhse.2021.16.Proc3.36 


\section{INTRODUCTION}

The relevance of the problem becomes evident in the research review devoted to the study of self-relationship and family attitudes and values in adolescence. However, there are not enough scientific works devoted to the topic consideration in the context of confessional affiliation among religiously practicing and ethnic Muslims (Murtazina \& Minullina, 2014; Murtazina \& Minullina, 2013; Murtazina, 2019; Murtazina, 2018). This work is intended to fill the gap. In the context of this problem the concept of "self-relationship" was the subject of a number of theoretical and experimental studies in the works of L.S. Vygotsky (2011), S.L. Rubinstein (1981), L.I. Bozhovich (2011), I.I. Chesnokova (1978); A.J. Varga (2010). The question of self-consciousness was analysed in general and methodological aspects in the context of a more common problem, as the development of personality.

Adolescence is a period of the life meaning awareness, the value-semantic sphere of personality. The study of youthful age was carried out by such scientists as L.I. Bozhovich (2011), I.S. Kon (1981), A.R. DrozdikovaZaripova (2015), G.F. Biktagirova (2016), S.V. Karpova (2009) and others. The significance of value orientations for youth is obvious as they form the basis of social actions, determine the degree of individual entry into the system of social institutions and communities. A major role in the formation of value orientations is played by religion. Since in the scientific and methodological literature the issues of self-relationship and family attitudes and values in adolescence of practicing and ethnic Muslims are poorly studied, the relevance of the study is caused by the aggravation of the contradiction between the objective need and the lack of this problem development. This general contradiction at the theoretical and methodological level is expressed in the form of a scientific problem: What are the characteristics of self-relationship and family attitudes and values in adolescence (on the example of ethnic and practicing Muslims).

\section{Theoretical and practical contribution of the article materials}

The theoretical significance of this work is that the research problem of self-relationship and family attitudes and values in adolescence (on the example of ethnic and practicing Muslims) is insufficiently studied despite the increased interest of this problem in foreign psychology and among domestic scientists.

The practical significance of the work is that the results of the study can be used in psychological practice, developmental psychology, educational psychology, social psychology.

\section{Goals and objectives of the study}

The purpose of this article is to identify the correlation of self-relationship and family attitudes and values in adolescence (on the example of ethnic and practicing Muslims). The following were identified as the main objectives: to carry out a theoretical analysis of the available literature data on the problem of self-relationship and family attitudes and values in adolescence (on the example of ethnic and practicing Muslims); to develop a research program, to select the necessary techniques and to collect and process empirical data; to analyse the data obtained and to determine the correlation of self-relationship and family attitudes and values in adolescence (on the example of ethnic and practicing Muslims)

\section{Analysis of Russian scientific and pedagogical literature}

Currently, there are a large number of works devoted to the problems of self-relationship. Within the framework of domestic psychology, the leading role of self-relationship in the functioning of the personality is noted by such researchers as L.I. Bozhovich (2011), I.S. Kon (1981), S.L. Rubinstein (1981), E.T. Sokolova (1989), I.I. Chesnokova (1978). The concept of self-relationship is based on a person's assessment of own traits, capabilities on relation to motives expressing the need for self-realization. This view of the self- 
relationship phenomenon is held by such representatives of the personality semantic concept as E.T. Sokolova (1989), V.V. Stolin (1983). The study of value orientations was carried out by domestic authors L.I. Bozhovich (2011), V.I. Slobodchikov and G.A. Tsukerman (1996), I.S. Kon (1981). However, scientific works devoted to the consideration of the issue in the context of confessional affiliation are not enough.

\section{Analysis of foreign studies}

It should be noted that the problem of self-relationship and family attitudes and values in adolescence is highly developed in foreign studies.

Analysing the approaches that consider the person self-relationship in foreign psychology, it can be noticed that this phenomenon is most fully represented in the theoretical concepts of R. Burns (1986), K.R. Rogers (2001), etc. Scientists as R. Plutchik, H. Kellermann and H.R. Conte (1979), R.S. Lazarus and S. Folkman (1984) have addressed the problem of coping strategies. Studying problem of the personality value orientations is reflected in the works of foreign scientists like Z. Freud (1999), E. Fromm (1992), M. Rokich (2009).

\section{MATERIALS AND METHODS}

\section{Research methods}

The following methods and techniques were used in the course of the study: theoretical analysis methods of scientific psychological literature, as well as empirical research method - testing, using the following techniques: Self-relationship research technique (Panteleev, 2003); Role expectations and claims in marriage methodology (Volkova, 2000); I.G. Senin's (1991) terminal values questionnaire; Family attitudes identification test (Ivanova, Bobyleva \& Zavodilkina, 2002).

Statistical processing was carried out with the method of correlation analysis according to Pearson and Student t-test.

\section{Research base}

The study was conducted in Kazan. The sample is represented by youthful age and 100 people participated in research: 50 of them are religious-practicing Muslims and 50 - ethnic Muslims. The average age of the subjects is from 18 to 23 years.

\section{Research stages}

The study was conducted in several stages. Stage 1 - identification of self-relationship in adolescence. Stage 2 - study of family attitudes and values in adolescence. Stage 3 - research and analysis of correlation between self-relationship and family attitudes and values in adolescence.

\section{RESULTS}

In order to study the structure of self-relationship, "Panteleev self-relationship research technique" was used in a group of ethnic and practicing Muslims.

The analysis shows that ethnic Muslims have the following structural components of self-relationship: selfconfidence, a sense of Self-force; ethnic Muslims respect themselves, they are satisfied with their undertakings and achievements, feel their competence and self-worth, a sense of self-esteem and the perceived value of their own "Self" for others. Subjects highly estimate their spiritual potential, wealth of their 
inner world, and highly appreciate their own uniqueness. Self-acceptance allows you to judge a sense of sympathy for yourself, acceptance of your internal motives. Ethnic Muslims tend to perceive all sides of their "Self", to accept themselves in the fullness of behavioural manifestations, characterized with internal conflict, the presence of doubts, disagreement with themselves, tendencies expressiveness toward heart-searching and reflection.

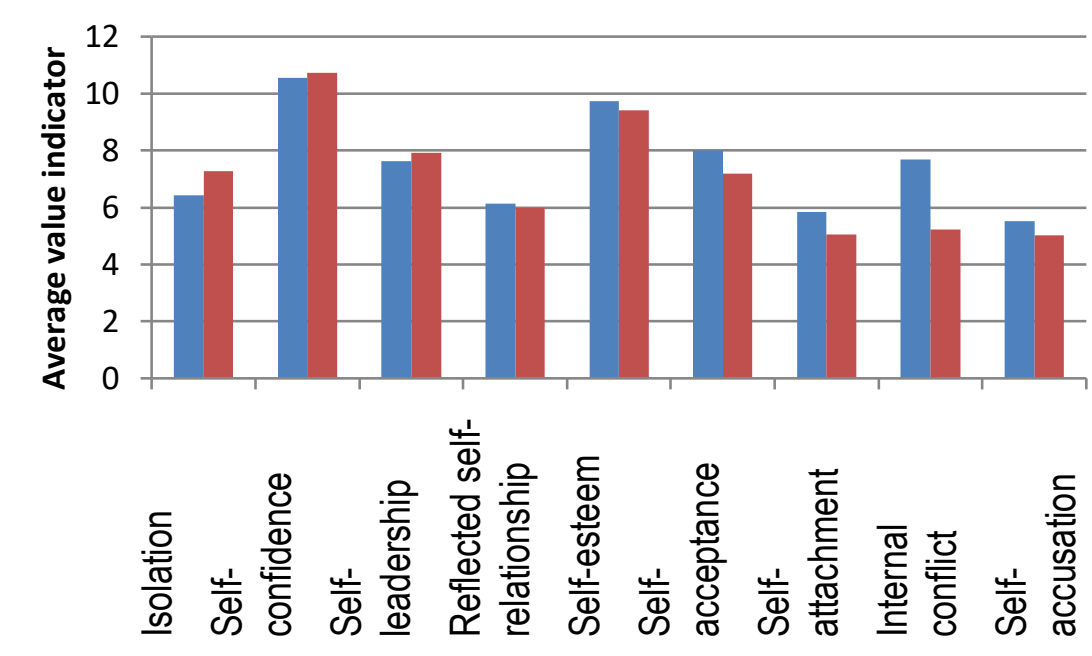

Indicators

Figure 1. Histogram of the self-relationship indicators distribution among ethnic and practicing Muslims in adolescence.
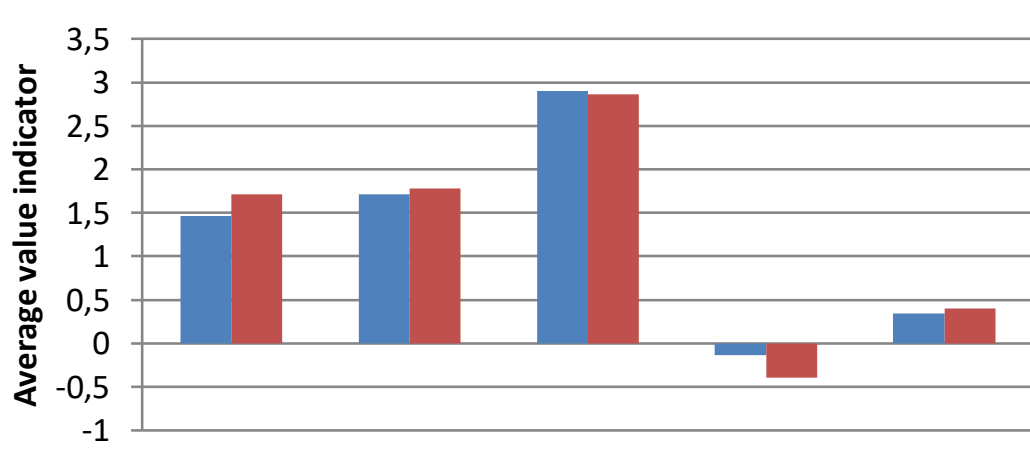

- Ethnic Muslims

- Practicing Muslims

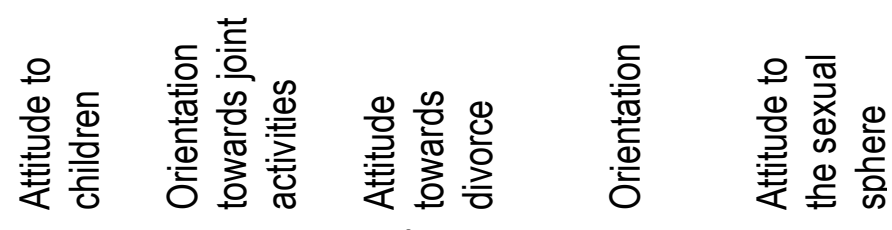

Indicators

Figure 2. Histogram of family attitudes indicators distribution among ethnic and practicing Muslims in adolescence.

Ethnic Muslims are not characterized by isolation, reflected self-esteem, the subject's idea about the ability to arouse respect, sympathy, self-attachment in other people revealing the degree of desire to change the 
current state. Religiously practicing Muslims are characterized by self-confidence, a sense of Self-force, selfesteem, the main source of their personality development. They consider themselves to be the regulator of achievements and successes. Less expressed components: reflected self-relationship, internal conflict, selfattachment among religiously practicing Muslims.

In order to study family attitudes, the "Family attitudes identification test" (Ivanova, Bobyleva \& Zavodilkina, 2002) methodology was used, the results of which are presented in Figure 2. For ethnic Muslims, family attitudes are significant as orientation towards joint activities in all spheres of family life. They have negative attitude towards divorce. Ethnic Muslims pay less attention to family attitudes towards children, the attitude to the equal structure of the family. The sexual sphere of family life is not significant for them. The family attitudes of practicing Muslims have revealed the importance of children in family life, an orientation towards mainly joint activities in all spheres of family life, and a negative attitude towards divorce. Equal arrangement of the family is uncharacteristic; the sexual sphere in family life is not significant.

The "Role expectations and claims in marriage" methodology was also used to study family attitudes. Figure 3

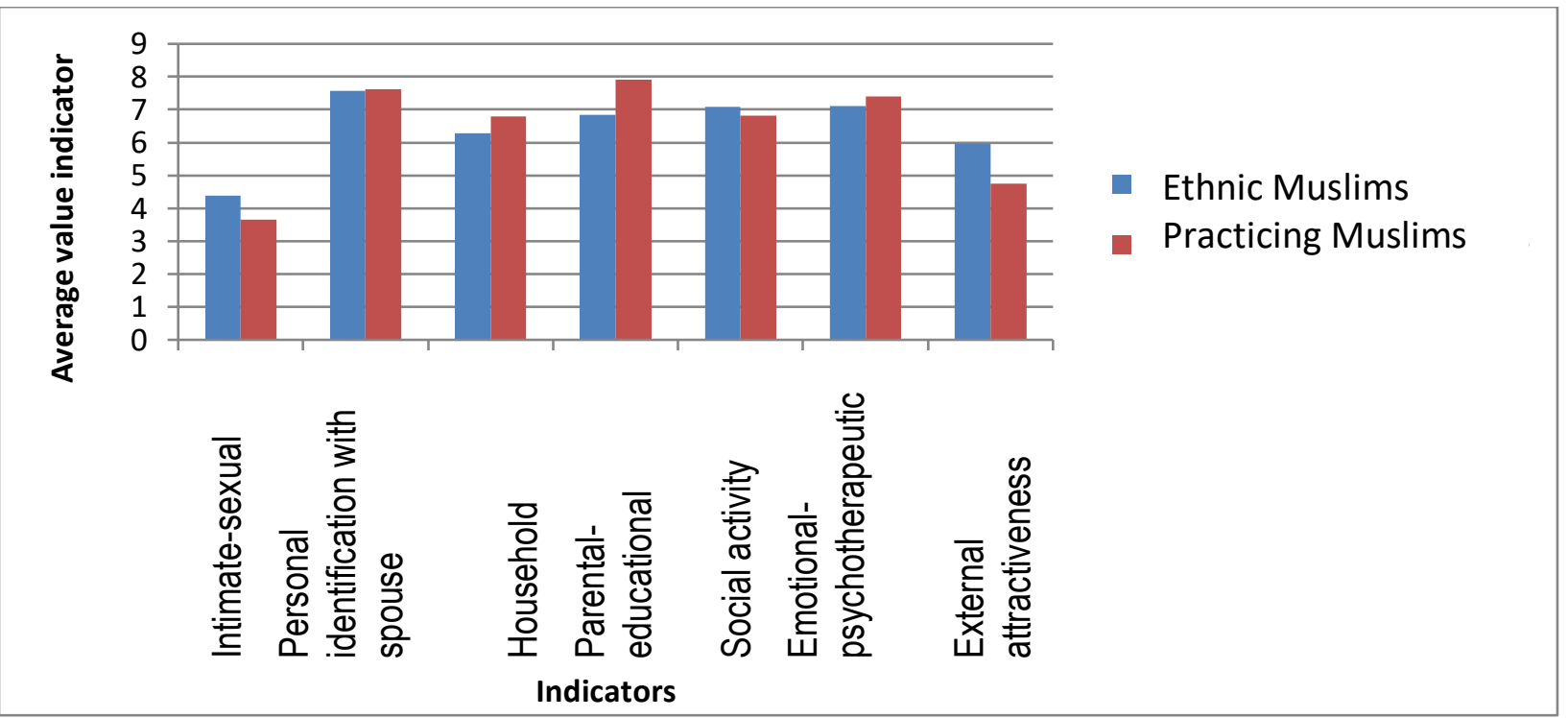

Figure 3. Histogram of family attitudes indicators distribution among ethnic and practicing Muslim in adolescence.

For ethnic Muslims family attitudes are significant: personal identification with spouse, social activity (professional, public), emotional-psychotherapeutic side of family life, and parental-educational settings. The intimate-sexual relations and the household function of the family are not significant. Little attention is paid to external attractiveness.

Practicing Muslims are very serious about parenting, personal identification with spouse, emotionalpsychotherapeutic side of marriage. Religiously practicing Muslims see the point of sharing interests, needs, value orientations, and ways of spending time with spouse. They pay attention to the moral and emotional support of family members, perceive marriage as an environment conducive to psychological relaxation and stabilization. 
However, for practicing Muslims appearance is of little importance. And there is also an underestimation of sexual relations in marriage.

The "I.G. Senin's (1991) terminal values questionnaire" technique was used to diagnose vital (terminal) values. (Figure 4). For ethnic Muslims the following terminal values are important: spiritual satisfaction which reflects a person's desire to obtain moral satisfaction in all areas of life, achievements, self-development, and high financial position. Less significant are the values of creativity, self-prestige for religiously practicing Muslims.

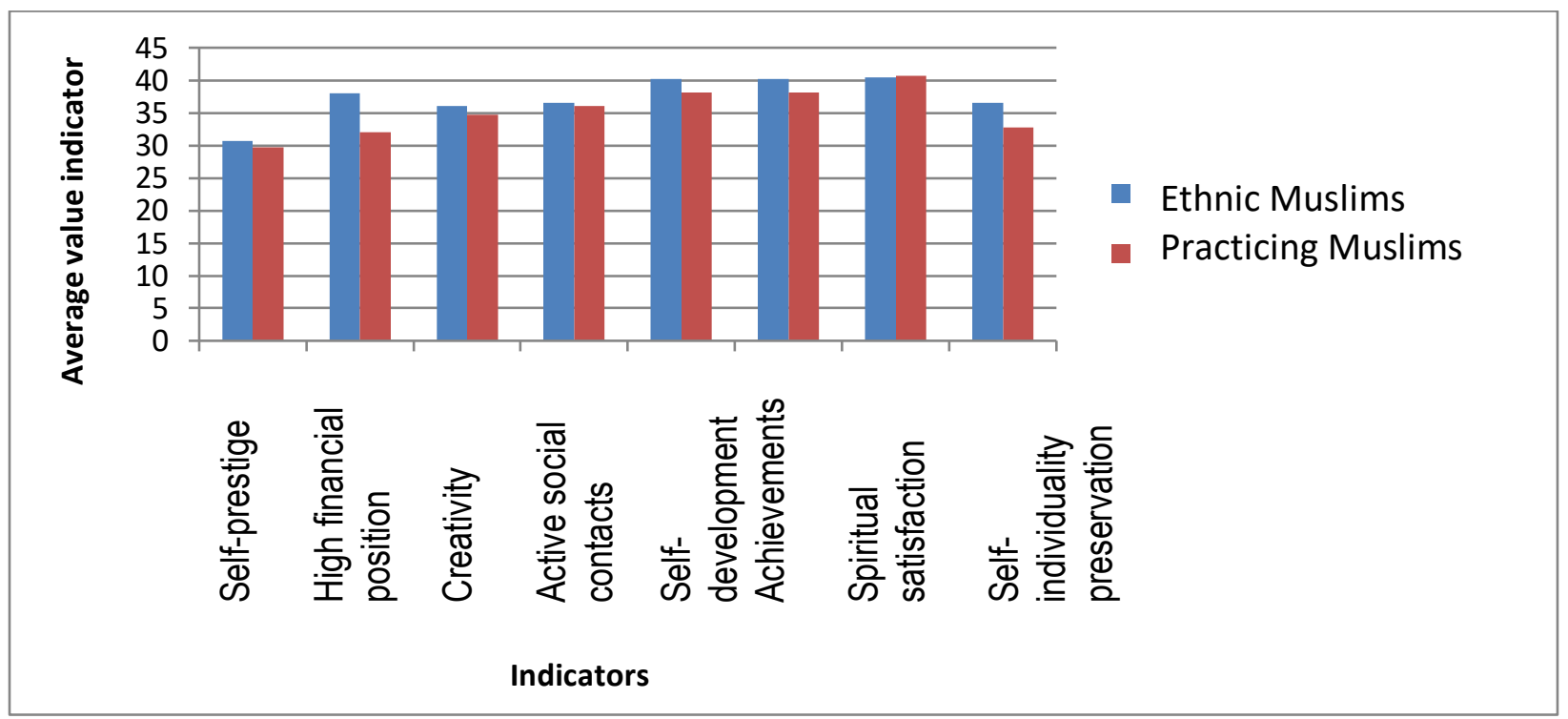

Figure 4. Histogram of terminal values indicators distribution among ethnic and practicing Muslims in adolescence.

Religiously practicing Muslims pay attention to spiritual satisfaction, seek to get moral satisfaction in all areas of their lives, self-development and achievement. Active social contacts, creativity, high financial position, and self-prestige are not typical.

Further, let us consider significant life spheres for ethnic and religiously practicing Muslims, Figure 5. For ethnic Muslims the spheres of professional activity are important, they strive to increase their level of education, expand their horizons, and spend their free time to their hobby. Less significant for ethnic Muslims is family problems solution and problems of public life.

For religiously practicing Muslims, it is important to increase the level of education, broaden their horizons, and solve problems related to work. Religiously practicing Muslims do not devote much time to their hobbies, have little interest in public life and little time to solving family problems.

The correlation between indicators of self-relationship and family attitudes and values in a sample of practicing Muslims revealed:

-"Attitude to children" and "reflected self-relationship" $\left(r_{\text {emp }}=0.42 ; p=.01\right)$;

-"Attitude to the sexual sphere" and "self-esteem" ( $r$ emp $=0.61 ; p=.01)$;

-"Attitude to the sexual sphere" and "self-acceptance" ( $\left.r_{\text {emp }}=0.43 ; p=.01\right)$; 
-"Household" and "self-confidence" ( $r$ emp $=0.43 ; p=.01)$;

-"Parenting" and "isolation" ( $\left.r_{\text {emp }}=0.41 ; p=.01\right)$;

-"Parenting" and "self-confidence" ( $r$ emp $=0.4 ; p=.01)$;

-"Social activity" and "self-esteem" $\left(r_{\text {emp }}=0.54 ; p=.01\right)$;

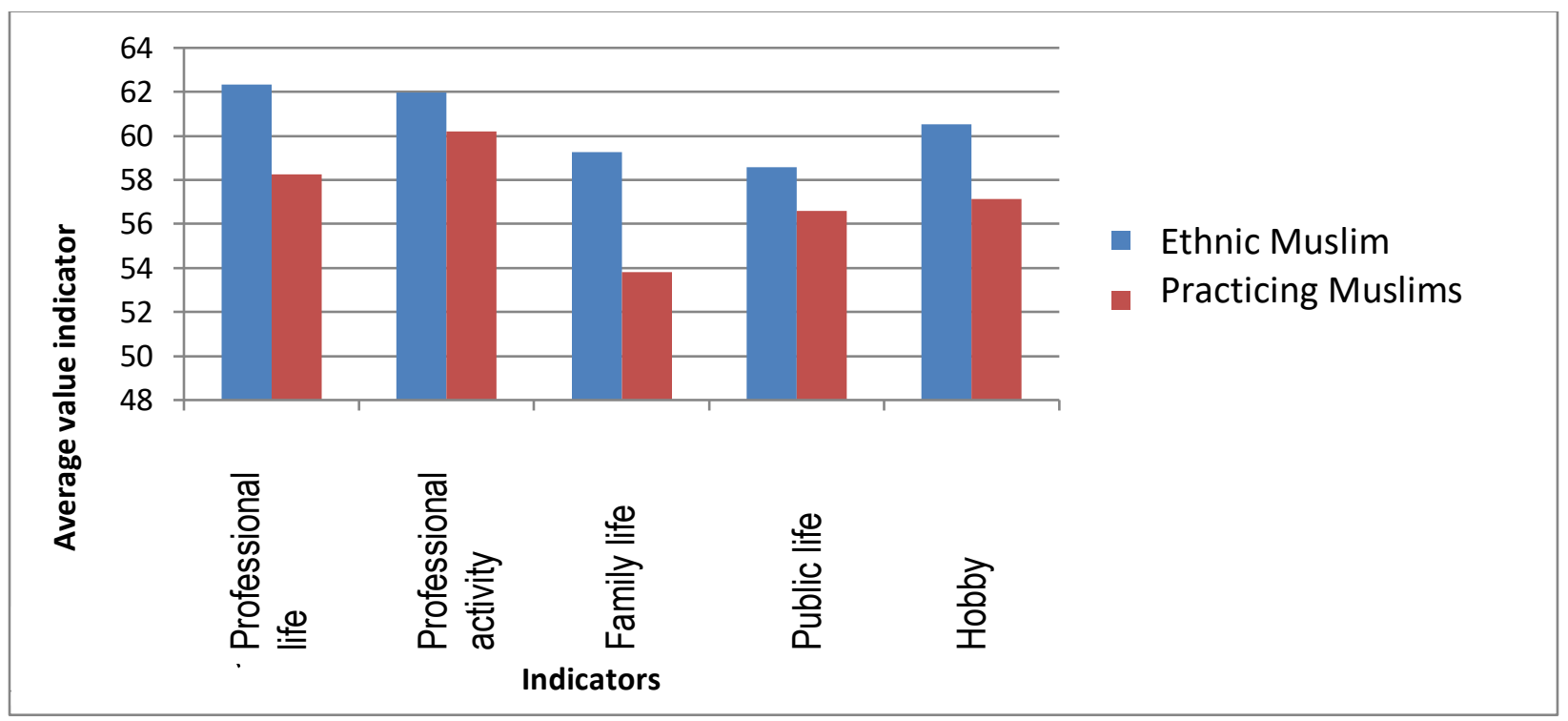

Figure 5. Histogram of life spheres indicators distribution among ethnic and practicing Muslims in adolescence.

These relationships can be explained as follows. With a high spiritual potential practicing Muslims perceive all sides of their "Self," respect themselves, and pay more attention to parental and sexual activity in family life. With the protective behaviour of perception themselves accepted by others, the importance of children in the family increases. The more practicing Muslims succumb to external circumstances, the less their desire for independence from others $(r$ emp $=-0.4 ; p=.01)$.

Among ethnic Muslims we found a correlation between the following indicators of family attitudes and selfrelationship:

- "Household" and "self-attachment" ( $\left.r_{\text {emp }}=0.63 ; p=.01\right)$;

-"Emotional-psychotherapeutic" and "self-leadership" $\left(r_{\text {emp }}=0.61 ; p=.01\right)$;

-"External attractiveness" and "self-acceptance" ( $r$ emp $=0.54 ; p=.01)$;

-"Emotional-psychotherapeutic" and "self-confidence" ( $r$ emp $=0.5 ; p=.01)$;

-"Parental-educational" and "self-confidence" ( $\left.r_{\text {emp }}=0.52 ; p=.01\right)$;

- "Social activity" and "self-confidence" $(r$ emp $=0.5 ; p=.01)$;

The greater the desire to preserve their qualities unchanged among ethnic Muslims, the more significant is the installation of the family's household function. Under high control of emotional reactions and experiences about themselves, the importance of the emotional-psychotherapeutic function of marriage increases.

Let's summarize the results of the correlation analysis indicators of self-relationship and values among ethnic Muslims in adolescence, the following were identified:

-"Creativity" and "self-confidence" ( $\left.r_{\text {emp }}=0.6 ; p=.01\right)$; 
-"Self-development" and "self-confidence" $\left(r_{\text {emp }}=0.62 ; p=.01\right)$;

- "Achievements" and "self-confidence" ( $\left.r_{\text {emp }}=0.74 ; p=.01\right)$;

-"Professional life" and "self-confidence" $(r$ emp $=0.6 ; p=.01)$;

- "Training and education" and "self-confidence" $\left(r_{\text {emp }}=0.72 ; p=.01\right)$;

-"Public life" and "self-confidence" ( $\left.r_{\text {emp }}=0.61 ; p=.01\right)$;

- "Self-prestige" and "self-confidence" $(r$ emp $=0.53 ; p=.01)$;

- "Active social contacts" and "self-confidence" $(r$ emp $=0.53 ; p=.01)$;

-"Self-individuality preservation" and "self-confidence" $(r=0.5 ; p=.01)$;

- "Family life" and "self-confidence" ( $r$ emp $=0.52 ; p=.01)$; emp

-"High financial position" and "self-acceptance" $(r$ emp $=0.54 ; p=.01)$;

In order to realize their creative possibilities, the interest of the person in objective information about his character, the desire to comprehend concrete and tangible results in different periods of life, the importance of professional activity sphere, the desire of the person to improve the level of education, the importance of society life, and the sense of Self-force increases.

\section{DISCUSSIONS}

As a result of the study, when testing hypotheses about the reliability of differences between the average values indicators in groups of ethnic and religiously practicing Muslims according to the method of researching self-relationship (Pantileev, 2003), the "isolation" indicator has significant differences. According to the "Role expectations and claims in marriage" methodology significant differences were revealed in the "parental-educational" family attitude. There were no significant differences in terminal values; these groups are prone to similar values and life spheres.

Data analysis shows that there is a correlation between self-relationship and family attitudes and values in groups of religiously practicing and ethnic Muslims. A group of ethnic Muslims is characterized with the correlation of self-relationship "self-confidence" indicator with values of self-prestige, creativity, active social contacts, self-development, achievement, self-individuality preservation, professional life, training and education, family life, social life, as well as family attitudes parental-educational, social activity and the emotional-psychotherapeutic side of family life. With the significance of the "reflected self-esteem" indicator, values are characterized with a high financial position, family life, public life, active social contacts, training and education, as well as with household family attitudes, intimate-sexual sphere, an indicator of external attractiveness.

Interconnections between the indicators of "self-confidence" with the family attitudes of parent-educational, household were revealed in the group of religiously practicing Muslims; the correlation of "self-esteem" indicator with family attitudes as a relation to the sexual sphere and social activity. Thus, summarizing aforesaid, it can be emphasized that ethnic Muslims have more correlation between indicators of selfrelationship and value than religiously practicing Muslims. In addition, religiously practicing Muslims have fewer connections between self-relationship and family attitudes and values.

\section{CONCLUSION}

The results of the study:

1. According to self-relationship indicators ethnic Muslims respect themselves and are satisfied with themselves. The general background of self-perception is positive. They are characterized by high 
requirements to themselves, which often leads to a conflict between "Self" real and "Self" ideal. Religiously practicing Muslims do not have an "internal conflict". They have a positive attitude toward themselves. They feel balance between their own capabilities and the requirements of surrounding reality.

2. The study of family attitudes in ethnic Muslims revealed low importance of children in the family. Religiously practicing Muslims focus on mostly joint activities. They have less loyal attitude to divorce, and the importance of children in family life.

3. The study of family attitudes according to the "Role expectations and claims in marriage" methodology among ethnic Muslims revealed that religiously practicing Muslims pay more attention to parenting than ethnic Muslims.

4. The study of significant life spheres revealed that high financial position is important for ethnic Muslims, and family life is important for practicing Muslim women.

5. Thus, the assumptions we put forward as a hypothesis of the research have been confirmed. There is a correlation between self-relationship and family attitudes and values in adolescence. The existing differences in the features of self-relationship and family attitudes and values in professing Islam (practicing Muslims) and secular, ethnic Muslims in adolescence have been confirmed. We hope that the results of this research can be useful in carrying out further work with students of Higher Educational Institutions, with students of the Theological Seminary and students of the Medrese. The materials of the article are of practical value for psychological and pedagogical support in the educational process, public awareness.

\section{ACKNOWLEDGEMENTS}

The work is performed according to the Russian Government Program of Competitive Growth of Kazan Federal University

\section{REFERENCES}

Bozhovich, L.I. (2011). Problems of personality formation: selected psychological works. Moscow: Institute of Practical Psychologists.

Burns, R. (1986). Development of self-concept and education. Moscow: Progress.

Chesnokova, I.I. (1978). Features of self-awareness development in ontogenesis. Principles of development in psychology. Moscow: Nauka.

Drozdikova-Zaripova, A.R. (2015). Features of value orientations in students - future teachers and psychologists. Modernization of Pedagogical Education: A collection of scientific works of the International Forum (June 3-5, 2015). Kazan: Publishing House "Brig".

Ivanova, N.P., Bobyleva, I.A. \& Zavodilkina, O.V. (2002). Socio-psychological adaptation of children in a substitute family. Moscow: BFRGTZ «Slovo».

Freud, Z. (1999). Theory and practice of child psychoanalysis. Moscow: April Press, JSC Eksmo-Pres.

Fromm, E. (1992). Man's Soul: TRANS. Moscow: Republic.

Karpova, S.V. (2009). The parent family as a factor that forms the way of life, Materials of the international scientific and practical conference. Petrozavodsk: Karelian state pedagogical University.

Biktagirova, G.F. (2016). The potential of Family Pedagogy discipline in the formation of students family values. Mathematics Education, 11(4), 809-817.

Murtazina, E.I. \& Minullina, A.F. (2014). Attitudes on the upbringing and family role of fathers in Islam. Modern problems of science and education, 3, 667-667. 
Murtazina, E.I. \& Minullina, A.F. (2013). Psychology of family presentations in the context of confessional affiliation Philology and culture. Philology and Culture Publishing House: Kazan (Volga) Federal University (Kazan), 3(33), 317-322.

Murtazina, E.I. (2018). The relationship of family education style and communication culture in adolescence crisis. European Proceedings of Social and Behavioural Sciences EpSBS, 45(45), 438 - 446. https://doi.org/10.15405/epsbs.2018.09.50

Murtazina, E.I. (2019). The Research of Self-Attitude and Coping Strategies in Adolescence in the Context of Religious Affiliation. ARPHA Proceedings. Part of: $V$ International Forum on Teacher Education: Part III: Educational Psychology, pp. 1411-1420. https://doi.org/10.3897/ap.1.e1339

Kon, I.S. (1981). Category I in psychology. Moscow: Nauka.

Lazarus, R.S., \& Folkman, S. (1984). Stress appraisal and coping. New York: Springer.

Pantileev, S.R. (2003). Self-relationship. Psychology of self-awareness. Samara: Ed. House of "BAHRAM-M".

Plutchik, R., Kellermann, H. \& Conte, H.R. (1979). A structural theory of ego defences and emotions. C.E. Isard (Eds.). Emotions in personality and psychopathology. New York: Plenum. https://doi.org/10.1007/978-1-4613-2892-6 9

Rogers, K.R. (2001). The formation of personality. Moscow: Publishing house EKSMO-Press.

Rokich, M. (2009). Methodology "Value Orientations". Moscow: Eksmo.

Rubinstein, S.L. (1981). Basics of General Psychology. Moscow: Pedagogy.

Senin, I.G. (1991). Terminal values questionnaire. Yaroslavl: Sodeistvie.

Slobodchikov, V.I. \& Tsukerman, G.A. (1996). Integral periodization of general mental development. Psychology issues, 5, 38-50.

Stolin, V.V. (1983). Personality self-awareness. Moscow: MSU.

Sokolova, E.T. (1989). Self-awareness and self-esteem with personality anomalies. Moscow: MSU.

Varga, A.J. (2010). Systemic family psychotherapy. St. Ptersburg: Speech.

Volkova, A.N. (2000). Psychological counseling of family conflicts. Bulletin of psychosocial and correctional rehabilitation work, 1, 105-112.

Vygotsky, L.S. (2011). Psychology. Moscow: EKSMO-Press.

This work is licensed under a Attribution-NonCommercial-NoDerivatives 4.0 International (CC BY-NC-ND 4.0). 